\title{
Case Files of the University of Massachusetts Fellowship in Medical Toxicology: Lethal Dose of Opioids Contained in an Elastomeric Capsule Labeled as Vancomycin
}

\author{
James M. Courtney, DO, Edward W. Boyer, MD, PhD
}

Department of Emergency Medicine, Division of Medical Toxicology, University of Massachusetts Medical School, Worcester, MA

\section{CASE STUDY}

A 67-year-old man presented to the emergency department (ED) with an alteration in mental status. His past medical history included hypertension, hyperlipidemia, vitamin $\mathrm{B}_{12}$ deficiency, and recurrent cellulitis. In addition to aspirin, atorvastatin, cyanocobalamin, and multivitamins, he received vancomycin $1 \mathrm{~g}$ IV every 12 hours via a peripherally inserted central catheter for MRSA cellulitis. Approximately 30 minutes after his wife began his most recent infusion of vancomycin, the patient began slurring his speech. When he became difficult to arouse, his wife activated Emergency Medical Services. The ambulance crew found the patient to be somnolent, but arousable, and breathing adequately. During transport to the ED, however, the patient became unresponsive and had depression in respiratory effort to the point that he required assisted ventilation with supplemental oxygen.

On arrival to the ED the patient's vital signs were: pulse 110 per minute, blood pressure $173 / 83 \mathrm{mmHg}$, respiratory rate 4 per minute, oxygen saturation 57\% while being assisted with 100\% oxygen via bag valve mask, and temperature $36.1^{\circ} \mathrm{C}$. On physical examination, there were no signs of physical trauma and pupils were 1-2 $\mathrm{mm}$ bilaterally. The patient had agonal respirations with rhonchi heard throughout the lung fields. Other than tachycardia, the cardiovascular and abdominal exams were without gross abnormalities. His skin was ashen, cool, and dry, with delayed capillary refill. The neurological examination showed no spontaneous movements and no response to painful stimuli. Because $2.2 \mathrm{mg}$ IV naloxone produced no improvement in respiratory depression, the patient was endotracheally intubated. Although the patient's wife denied access to or the use of narcotics, the patient's qualitative comprehensive urine toxicology screen (which could identify 1043 drugs and other chemicals) detected morphine, codeine, and naloxone.

\section{What are the appropriate dosages for the opioid antagonists that are used clinically?}

Naloxone was introduced to the US market in 1967, and since that time it has become the preferred antidote for opiate overdose. Naloxone is part of the "coma cocktail," a combination of naloxone, dextrose, and thiamine that is sometimes administered empirically to intoxicated patients with depressed mental status. Since the introduction of naloxone to the pharmaceutical market in the late 1960s, doses of intravenous naloxone between $0.8 \mathrm{mg}$ and $2.0 \mathrm{mg}$ were used to help establish the diagnosis of opioid overdose [1]. A positive response to these doses of naloxone was considered to be an improvement of respiratory effort and an improvement in the level of consciousness. However, the observation that overzealous administration of naloxone could precipitate opioid withdrawal led to the recommendation that serial doses of $0.1-0.2 \mathrm{mg}$ naloxone be used in patients who are suspected of being opioid dependent, to help restore respiratory effort without precipitating acute opioid withdrawal [2].

Naloxone, and its congeners naltrexone and nalmefene, are competitive antagonists at the $\mu-, \kappa-$, and $\Delta$-opiate receptors [3]. Naloxone and nalmefene are available in parenteral formulations, while naltrexone is available in only an oral formulation [4]. In one study, which used a dual detector system to observe opiate receptor occupancy time, the authors found that nalmefene occupied $\mu$-receptors in the brains of 8 healthy human volunteers longer than did equipotent doses of naloxone [5]. When the receptors were no longer occupied by either naloxone or nalmefene, a radiolabeled opiate was able to occupy the receptors and

Keywords: opioids, elastomeric capsule, monoacetylmorphine Note: There was no outside funding of any kind used for this study.

Corresponding author: James M. Courtney, DO, Department of Emergency Medicine, University of Massachusetts, 55 Lake Avenue North, Worcester, MA 01655. Email: jcourtn@gmail.com 
Table 1: Pharmacokinetic data for select opiate antagonists

\begin{tabular}{llll}
\hline & Formulations & \multicolumn{1}{c}{ T 1/2 } & $\begin{array}{l}\text { Opiate Receptor } \\
\text { Occupancy Time }\end{array}$ \\
\hline Naloxone & $\begin{array}{l}\text { Enteral and } \\
\text { parenteral }\end{array}$ & $\sim 1$ hour & $\begin{array}{l}2 \text { hours } \pm 1.6 \text { hours for } \\
\text { a 2-mg dose }\end{array}$ \\
\hline Nalmefene & $\begin{array}{l}\text { Enteral and } \\
\text { parenteral }\end{array}$ & $\begin{array}{l}\text { 6.5-15 } \\
\text { hours }\end{array}$ & $\begin{array}{l}28.7 \text { hours } \pm 5.9 \text { hours } \\
\text { for a 1-mg dose }\end{array}$ \\
Naltrexone & Enteral & $3.9-10$ hours & \\
\hline
\end{tabular}

lead to analgesia and central nervous system depression. It is receptor occupancy time that dictates duration of clinical effect, rather than plasma drug levels [5]. The plasma half-lives and receptor occupancy times of these opioid antagonists are presented in Table 1 [5-8]. Nalmefene has similar potency, effect, and volume of distribution compared to naloxone, but its more prolonged half-life is likely due in part to enterohepatic recirculation $[9,10]$. A double-blind, randomized, multicenter ED study of patients presenting with narcotic overdose compared naloxone $2 \mathrm{mg}$ IV to nalmefene $1 \mathrm{mg}$ or nalmefene $2 \mathrm{mg}$ IV every 5 minutes based on clinical need to a maximum of 4 total doses. Using outcome measures of respiratory rate, calculated score on a validated neurobehavioral assessment scale [11] and calculated score on a nonvalidated opiate withdrawal scale, all three groups were equally efficacious with no statistically significant differences between them [12]. The authors concluded that nalmefene represents another option for treating long-acting opiate overdoses, especially in opiate-naïve patients such as children. These results should be interpreted with caution, since long-acting opioids in overdose may have a duration of action longer than that of therapeutic doses of nalmefene.

\section{How should a patient with recurrent respiratory depression from opioid toxicity be managed?}

Naloxone has a shorter duration of action than that of many opioids [13]. The implications of this pharmacological effect are that patients may require repetitive naloxone doses to maintain an alert mental status. A 2-phase clinical trial was undertaken to determine the optimal dosing regimen for continuous naloxone infusion to prevent recurrent respiratory depression [14]. Recommendations from this study are that $2 / 3$ of the initial bolus dose of naloxone necessary to reverse respiratory depression should be administered every hour as an infusion. A repeat bolus of half the initial dose can be administered 15 minutes after the first to maintain a steady state of opioid antagonism [14]. The pediatric literature also supports use of naloxone infusion to reverse coma and respiratory depression following exposure to opioids, including suboxone [15].

\section{CASE CONTINUATION}

A home infusion medication supply service had delivered 5 sealed elastomeric capsules labeled as vancomycin on the day of

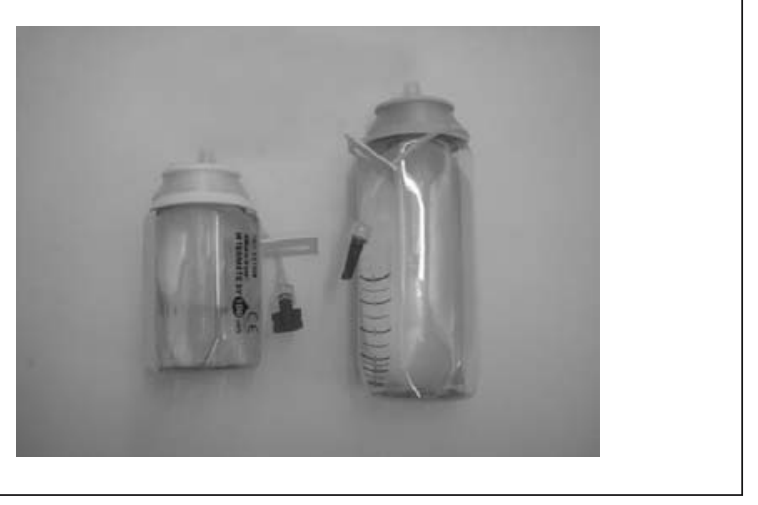

Figure 1: Two representative elastomeric capsules.

the patient's presentation. The original elastomeric container administered by the patient's wife was not available for testing, but the Massachusetts State Forensic Laboratory confiscated the remaining containers from the same delivery. These containers, all of which were unopened, were labeled as vancomycin $1 \mathrm{~g}$ in $240 \mathrm{~mL}$ of normal saline (Figure 1). Using GC-MS, the state forensic laboratory confirmed that the alkaloidal contents of the remaining elastomeric capsules were $10 \%$ codeine, $4.4 \%$ 6-monoacetylmorphine, and $84 \%$ morphine. No vancomycin was identified in the infusion bottles. Because of the presence of 6-monoacetylmorphine, the initial compound in these elastomeric capsules was most likely heroin. With the concurrent presence of codeine, a precursor for the "homebake" synthesis of heroin, it was very likely that this elastomeric capsule contained an illicit heroin preparation that was being distributed in elastomeric capsules.

\section{What is an elastomeric capsule?}

Outpatient Parenteral Antimicrobial Therapy (OPAT) is an emerging therapeutic modality that has been shown to be both cost effective and efficacious [16-19]. There are four typical methods of OPAT delivery: (1) self-administration at home, (2) administration by a visiting nurse in the home, (3) drug administration at a infusion center, or (4) drug administration at a skilled nursing facility [16]. The first 2 methods of administration use gravity feed to administer the medication to the patient, whereas the latter 2 methods employ infusion pumps. The elastomeric reservoir capsule system, in use since the 1980s, incorporates a pressurized, expandable rubber bladder within a rigid plastic outer container [20]. When connected to an infusion line, the liquid contained within the bladder is delivered at a rate determined by the pressure inside the rubber bladder, along with the temperature and viscosity of the liquid $[20,21]$. This allows IV medications to be delivered at defined rates without the need for infusion pumps, eliminating the need for trained professionals to administer pharmaceuticals.

\section{How is heroin synthesized?}

Heroin is a semisynthetic opioid derived from the natural product morphine [22]. First synthesized in 1874 by Charles Alder 
Wright in London, heroin was not marketed until 1898 by Bayer and Co., when it was sold as an antitussive for use in the tuberculosis epidemic [22]. Heinrich Dresser, a chemist for Bayer, derived the brand name "Heroin" from Greek linguistic sources, through German. The Greek work "heros" refers to demigods within Greek mythology, whereas the German word "heroisch" was what the employees at Bayer, whom heroin was first tested on, called it because it made them feel heroic [22]. Heroin is produced by the diacetylation of morphine, producing 3,6-diacetylmorphine. Yields of $83 \%$ can be achieved with the reaction of morphine with acetic anhydride, while acid-catalyzed crosscondensation of morphine with acetic acid is slightly less efficient [23]. This latter method produces more monoacetylmorphine at both the 6- and 3-positions (6-MAM and 3-MAM, respectively). A third method of heroin production is the stepwise "homebake" method of converting codeine to heroin. The first step in the conversion of codeine to morphine involves O-demethylation with pyridine hydrochloride. The morphine is then acetylated using an anhydride, as previously discussed [24]. This process, while fairly simple, has poor overall yields, as $2 \mathrm{~g}$ of readily available codeine produces only 50-200 mg of impure heroin product [24]. Once synthesized, the water solubility of heroin can be increased by conversion of the insoluble free base to a hydrochloride salt. The base form tends to be brown or black, while the salt is white [25]. In the US, the prevalence of heroin base or hydrochloride salt depends on the drug market [25]. Although the United States Department of Justice reports that demand for heroin has remained stable, worldwide heroin production and healthcare facility admission rates for primary heroin treatments in the US both continue to rise [26].

\section{How is heroin metabolized?}

In human plasma, heroin is rapidly hydrolyzed by plasma cholinesterases as well as human carboxylesterase-2. The acetyl group at the 3 position is removed preferentially to produce 6-monoacetylmorphine (6-MAM), which is subsequently hydrolyzed to morphine. Morphine undergoes glucuronidation to morphine-6-glucuronide and morphine-3-glucuronide, the latter being the major metabolite [27]. After IV administration, heroin remains detectable in the serum between 10-40 minutes; virtually none is excreted unchanged in the urine [28]. Peak concentrations of 6-MAM occur within 3 minutes of administration. Because of its lipophilicity, 6-MAM may account for much of the CNS effects associated with heroin administration [28].

\section{Does diacetylmorphine degrade into monoacetylmorphine and morphine in vitro?}

Depending on the temperature and $\mathrm{pH}$ of a solution, diacetylmorphine undergoes degradation to 6-monoacetylmorphine and morphine in vitro [29]. A study examining the degradation rates of various concentrations of heroin maintained at various storage temperatures showed that regardless of concentration, significant degradation of a diacetylmorphine solution to both 6-MAM and morphine occurs [30]. The rate of these transformations accelerates at temperatures greater than $>4^{\circ} \mathrm{C}$ and in alkaline solution[30]. Another study observed first-order kinetics in spontaneous degradation and that the degradation rate was much higher in alkaline solution. Over a period of 14 days, no degradation of 6-MAM in aqueous solution occurred when the $\mathrm{pH}$ of the buffered solution was 8.5 or lower. However, as the $\mathrm{pH}$ increased to a peak of 11.0, the half-life of 6-MAM in aqueous solution decreased to less than $1 \%$ of its previous value [31]. Because the free base of heroin would be expected to produce an alkaline solution, rates of degradation will be greater for solubilized heroin base than for salt forms of the drug.

\section{CASE CONTINUATION}

The patient was admitted to the ICU and managed with supportive care. He was discharged with intact neurological status 25 days later after multiple complications including pneumonia, atrial fibrillation, pneumothorax and bacterial tracheitis, treated with tube thoracostomy and tracheostomy, respectively.

The case was referred to local and state police departments and the Commonwealth of Massachusetts Department of Public Health Drug Control Board. The home infusion company was also immediately notified to prevent similar occurrences. Unfortunately, the source of the narcotics within the elastomeric container has not yet been identified.

\section{What is the incidence of pharmacy mislabeling?}

Pharmacists are legally responsible for the proper labeling of prescription drugs. Failure to do so mandates reporting to state authorities; reporting to the FDA MedWatch program, while desirable, is not considered mandatory by law. According to the FDA MedWatch Safety Page, in May 2001, of the 273 reports made to MedWatch, 68 (20\% of the total) were classified as labeling error [32]. Of the MedWatch mislabeling cases, the single drug that was associated most often with medication errors was morphine, accounting for $8 \%$ of the total number of reports. While pharmacy mislabeling remains a potential source of misidentification in this case, the presence of degradation products of heroin, specifically 6-MAM, makes this possibility much less likely. If this were a simple case of mislabeling morphine for vancomycin, one would not expect to see 6-MAM in the solution because morphine will not spontaneously acetylate to form monoacetylmorphine.

\section{What should the response be to medication adulteration incidents?}

Upon receiving the results of the contents of the elastomeric capsule, the toxicologist on call alerted the state drug control program, the municipal police department where the pharmaceutical supply was located, and the police in the municipality where the incident took place. A phone call was also placed to the regional office of the pharmaceutical supply company to alert them to a potential mislabeling problem and therefore a possible public health threat. As this case is still legally under investigation, we 
can only speculate as to whether this was a simple case of pharmaceutical mislabeling or a narcotics trafficking mistake.

\section{CONCLUSION}

This case describes the adulteration of a vancomycin elastomeric capsule with opioids that likely arose from degradation of heroin [29-31]. Although the clinical management of patients suffering the effects of contaminated drugs may be straightforward, the public health risk associated with adulterated pharmaceuticals and drug delivery devices should mandate a brisk response from governmental regulatory agencies.

\section{REFERENCES}

1. Handal KA, Schauben JL, Salamone FR. Naloxone. Ann Emerg Med 1983;12:438-445.

2. Martin WR, Naloxone. Ann Intern Med 1976;85:765-768.

3. Foord SM, Bonner TI, Neubiq RR, Rosser EM, Pin JP, Davenport AP, et al. International Union of Pharmacology. XLVI. G protein-coupled receptor list. Pharmacol Rev 2005;57:279-288.

4. Howland MA. Antidotes in Depth-Opioid Antagonists. 8th ed. Goldfrank's Toxicologic Emergencies. In: Flomenbaum NE, Goldfrank LR, Lewin NA, Howland MA, Hoffman RS, Nelson LS, eds. 2006. New York: McGraw-Hill. 614-619.

5. Kim S, Wagner HN, Villemagne VL, Kao PF, Dannals RF, Ravert HT, et al. Longer occupancy of opioid receptors by nalmefene compared to naloxone as measured in vivo by a dual-detector system. J Nucl Med 1997;38:1726-1731.

6. Ngai SH, Berkowitz, BA, Yang JC, Hempstead J, Spector S. Pharmacokinetics of naloxone in rats and in man: basis for its potency and short duration of action. Anesthesiology 1976;44: 398-401.

7. Dixon R, Gentile J, Hsu HB, Hsiao J, Howes J, Garg D, et al. Nalmefene: safety and kinetics after single and multiple oral doses of a new opioid antagonist. J Clin Pharmacol 1987;27: 233-239.

8. Crabtree BL. Review of naltrexone, a long-acting opiate antagonist. Clin Pharm 1984;3:273-280.

9. Glass PS, Jhaveri RM, Smith LR. Comparison of potency and duration of action of nalmefene and naloxone. Anesth Analg 1994;78:536-541.

10. Matzke GR, Frye RF, Alexander AC, Reynolds R, Dixon R, Johnston J, et al. The effect of renal insufficiency and hemodialysis on the pharmacokinetics of nalmefene. J Clin Pharmacol 1996;36:144-151.

11. Chernik DA, Tucker M, Gigli B, Yoo K, Paul K, Laine H, et al. Validity and reliability of the Neurobehavioral Assessment Scale. J Clin Psychopharmacol 1992;12:43-48.

12. Kaplan JL, Marx JA, Colabro JJ, Gin-Shaw SL, Spiller, JD, Spivey WL, et al. Double-blind, randomized study of nalmefene and naloxone in emergency department patients with suspected narcotic overdose. Ann Emerg Med 1999;34:42-50.
13. Wang DS, Sternbach G, Varon J. Nalmefene: a long-acting opioid antagonist. Clinical applications in emergency medicine. J Emerg Med 1998;16:471-475.

14. Goldfrank L, Weisman RS, Errick JK, Lo MW. A dosing nomogram for continuous infusion intravenous naloxone. Ann Emerg Med 1986;15:566-570.

15. Lewis, JM, Klein-Schwartz W, Benson BE, Oderda GM, Takai S. Continuous naloxone infusion in pediatric narcotic overdose. Am J Dis Child 1984;138:944-946.

16. Bernard L, El-Hajj, Pron B, Lotthé A, Gleizes V, Signoret F, et al. Outpatient parenteral antimicrobial therapy (OPAT) for the treatment of osteomyelitis: evaluation of efficacy, tolerance and cost. J Clin Pharm Ther. 2001;26:445-451.

17. Chary A, Tice AD, Martinelli LP, Liedtke LA, Plantenga MS, Strausbaugh LJ, et al. Experience of infectious diseases consultants with outpatient parenteral antimicrobial therapy: results of an emerging infections network survey. Clin Infect Dis 2006;43:1290-1295.

18. Tice AD. The use of outpatient parenteral antimicrobial therapy in the management of osteomyelitis: data from the Outpatient Parenteral Antimicrobial Therapy Outcomes Registries. Chemotherapy 2001;47 Suppl 1:5-16.

19. Wai AO, Frighetto L, Marra CA, Chan E, Jewesson PJ. Cost analysis of an adult outpatient parenteral antibiotic therapy (OPAT) programme. A Canadian teaching hospital and Ministry of Health perspective. Pharmacoeconomics 2000;18:451-457.

20. Kwan JW. High-technology i.v. infusion devices. Am J Hosp Pharm 1989;46:320-335.

21. Skryabina EA, Dunn TS. Disposable infusion pumps. Am J Health Syst Pharm 2006;63:1260-1268.

22 . Sneader W. The discovery of heroin. Lancet 1998; 352:1697-1699.

23. Odell LR, Skopec J, McCluskey A. A 'cold synthesis' of heroin and implications in heroin signature analysis utility of trifluoroacetic/acetic anhydride in the acetylation of morphine. Forensic Sci Int 2006;164:221-229.

24. Bedford KR, Nolan SL, Onrust R, Siegers JD. The illicit preparation of morphine and heroin from pharmaceutical products containing codeine: 'homebake' laboratories in New Zealand. Forensic Sci Int 1987;34:197-204.

25. Nelson LS. Opioids. In: Flomenbaum NE, Goldfrank LR, Lewin NA, Howland MA, Hoffman RS, Nelson LS, eds. Goldfrank's Toxicologic Emergencies. 8th ed. 2006. New York: McGraw-Hill. 590-613.

26. National Drug Intelligence Center: National Drug Threat Assessment 2005 Summary Report. February 2005. http://www. usdoj.gov/ndic/pubs11/13846/heroin.htm. Accessed 11/23/07.

27. Faura CC, Collins SL, Moore RA, McQuay HJ. Systematic review of factors affecting the ratios of morphine and its major metabolites. Pain 1998;74:43-53.

28. Rook EJ, Huitema AD, van den Brink W, van Ree JM, Beijnen JH. Pharmacokinetics and pharmacokinetic variability of heroin and its metabolites: review of the literature. Curr Clin Pharmacol 2006;1:109-118. 
29. Beaumont JM. Stability study of aqueous solutions of diamorphine and morphine using HPLC. Pharm J 1982; 229:39-41.

30. Omar OA, Hoskin, PJ, Johnston A, Hanks GW, Turner P. Diamorphine stability in aqueous solution for subcutaneous infusion. J Pharm Pharmacol 1989;41:275-277.
31. Barrett DA, Dyssegaard AL, Shaw PN. The effect of temperature and $\mathrm{pH}$ on the deacetylation of diamorphine in aqueous solution and in human plasma. J Pharm Pharmacol 1992;44:606-608.

32. Thomas MR, Holquist C, Phillips J. Med error reports to FDA show a mixed bag. Drug Topics 2001; October 1:23-24.

\section{BRIEF TOXICOLOGY COMMUNICATIONS}

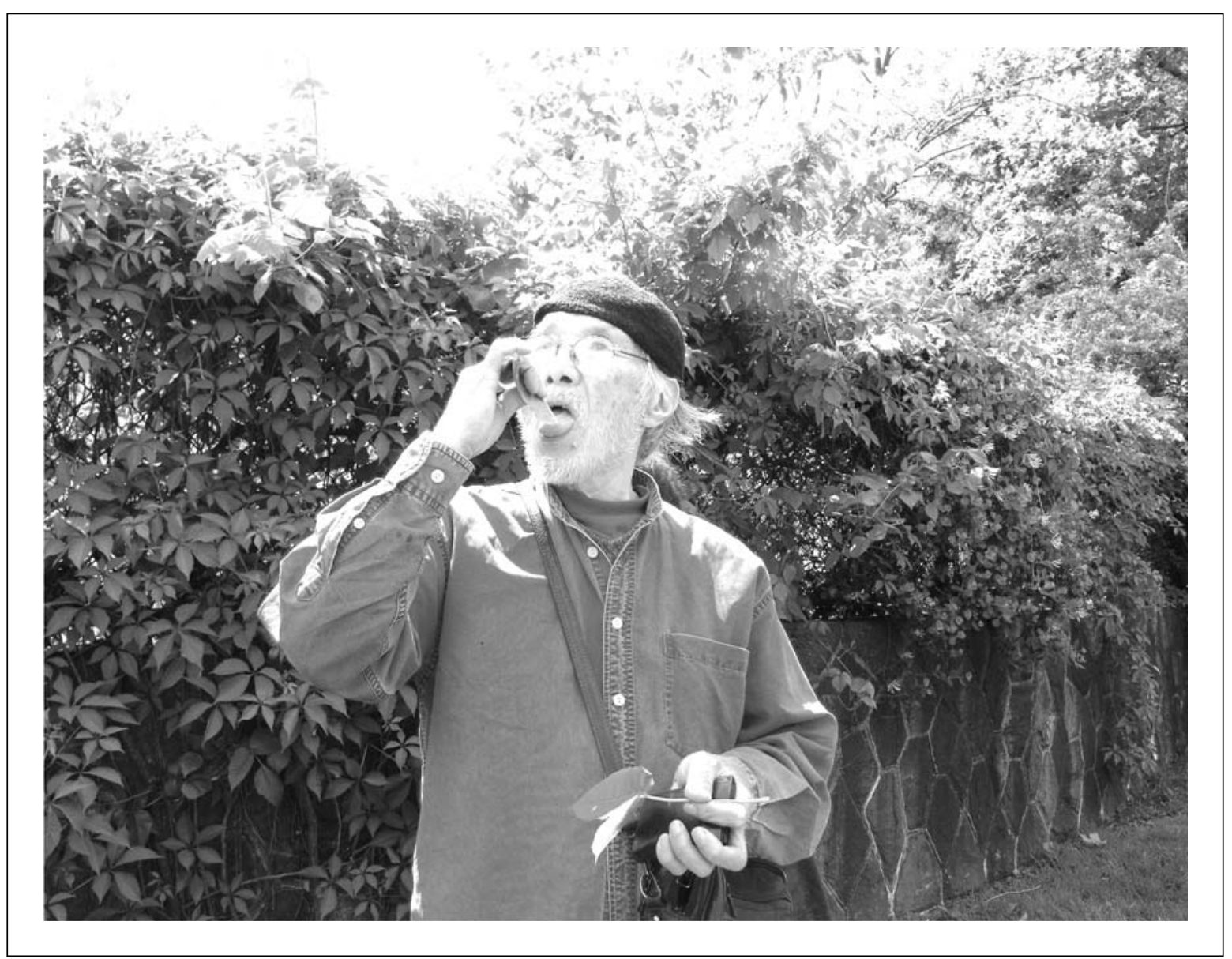

What is this plant and why is this Japanese artist eating it? For the answer, see page 201 